\title{
Duodenal Perforation
}

National Cancer Institute

\section{Source}

National Cancer Institute. Duodenal Perforation. NCI Thesaurus. Code C78259.

A rupture in the duodenal wall due to traumatic or pathologic processes. 